\title{
Etnobotânica da flora medicinal de quintais na comunidade Mamangal, Igarapé-Miri, PA
}

Ethnobotany of the medicinal flora of backyards in the community Mamangal, Igarapé-Miri, PA

\author{
E. Q. dos Santos*1; J. F. S. Costa ${ }^{1}$; M. G. S. Pereira ${ }^{1}$; J. M. Costa ${ }^{2}$; R. L. de Sousa ${ }^{1}$ \\ ${ }^{1}$ Universidade Federal do Pará - UFPA, Campus Universitário de Abaetetuba - Educação do Campo, 684400-000, \\ Abaetetuba, Pará, Brasil \\ ${ }^{2}$ Instituto Federal do Pará - IFPA, Campus de Abaetetuba, 684400-000, Abaetetuba, Pará, Brasil \\ *eldagomesufpa@gmail.com
}

(Recebido em 14 de março de 2019; aceito em 27 de maio de 2019)

\begin{abstract}
Estudos de etnobotânica são importantes em comunidades amazônicas, pois as plantas medicinais constituem uma importante fonte de recurso utilizado no combate e prevenção de diversas afecções tropicais, em comunidades distantes dos grandes centros médicos e com baixo poder aquisitivo. $\mathrm{O}$ estudo foi conduzido na comunidade Mamangal, que está situada às margens do Rio Mamangal Grande, na cidade de IgarapéMiri-PA. Neste estudo objetivou-se pesquisar os conhecimentos tradicionais sobre a manipulação, os usos e as indicações terapêuticas das plantas usadas pelos moradores da comunidade Mamangal. A seleção dos colaboradores foi realizada através da metodologia "bola de neve". Em nosso estudo foram entrevistados 20 participantes na faixa etária de 30 a 76 anos, e a planta com predomínio de uso foi o mastruz, para tratar de afecções intestinais. A flora medicinal dos quintais da comunidade Mamangal apresentou elevada diversidade de espécies (47 etnoespécies), várias indicações terapêuticas (31 indicações) e cinco formas de preparo.

Palavras-Chave: Plantas cultivadas em quintais, conhecimento tradicional das plantas medicinais, fitofarmacopéia local.
\end{abstract}

Ethnobotanical studies are important in Amazonian communities, since medicinal plants are an important resource used in the combat and prevention of various tropical diseases, in communities far from large medical centers and with low purchasing power. The study was conducted in the Mamangal community, which is located on the banks of the Mamangal Grande River, in the city of Igarapé-Miri-PA. This study aimed to research the traditional knowledge about the manipulation, uses and therapeutic indications of the plants used by the residents of the Mamangal community. The selection of the collaborators was performed through the "snowball" methodology. In our study 20 participants were interviewed in the age group of 30 to 76 years, and the predominant plant was mastruz, to treat intestinal affections. The medicinal flora of the backyards of the community Mamangal presented high species diversity (47 ethnospecies), several therapeutic indications (31 indications) and five forms of preparation.

Key words: Plants grown in backyards, traditional knowledge of medicinal plants, local phytopharmacopoeia.

\section{INTRODUÇÃO}

As plantas medicinais constituem um importante recurso utilizado na prevenção e no tratamento de afecções em diversas comunidades ao longo do território brasileiro, como demonstram estudos realizados no semiárido piauiense [1], Imperatriz-MA [2], São José de Espinhas-PB [3], Sertão do Ribeirão- SC [4], Volta Redonda-RJ [5], Manacapuru-AM [6], Marudá-PA [7], Anapu-PA [8], Belém-PA [9] e Abaetetuba-PA [10].

O cultivo de plantas medicinais em ambientes produtivos como os quintais faz parte da cultura, dos costumes e da forma como cada família se estabelece em uma determinada localidade [11]. Nos centros urbanos o espaço peridomiciliar vem diminuindo em função de novas construções e consequentemente, tem se observado o predomínio do cultivo das plantas ornamentais no interior das residências [12]. Contrastando com essa realidade, um estudo realizado em uma comunidade rural no município de Abaetetuba (PA), evidenciou que as famílias residentes nessa localidade continuam plantando, fazendo a colheita dos produtos agrícolas e praticando as relações comerciais, de modo semelhante aos fundadores da comunidade no início da década de 90 [13]. Entre os povos Tremembé, no Ceará, as plantas ritualísticas são as mais relevantes, com destaque para as frutas murici e batiputá, consideradas sagradas e por isso são realizadas grandes comemorações nos períodos de colheitas [14]. Em Cuiabá, Mato Grosso, as plantas medicinais foram as mais representativas, usadas para cura e prevenção de doenças [15]. Esses estudos sugerem uma grande 
diversidade de usos das plantas medicinais ao longo do território brasileiro, sendo que espécies como boldo, mastruz e gengibre são registradas frequentemente em estudos etnobotânicos [16, 17, 18] e outras como andiroba [19] e aroeira [20], mais restritas as regiões norte e no nordeste.

A utilização das plantas medicinais em diversas comunidades amazônicas perpassa o tratamento de doenças descritas pela OMS (Organização Mundial da Saúde), incluindo também aquelas do universo das religiões estabelecidas dentro da cultura das comunidades como o quebranto, mau olhado, conquista da pessoa amada, quebra de feitiços e a conquista de vagas no mercado de trabalho [11]. Além dessas finalidades, segundo Ferreira e Tavares-Martins (2016) [21], as plantas classificadas como místicas são utilizadas como amuletos para proteção, cultivadas para espantar mal olhado, benzer crianças e banhos tradicionais.

As comunidades ribeirinhas da Amazônia estão localizadas longe dos grandes centros médicos do Brasil e possuem baixo poder aquisitivo, sendo assim a utilização de plantas medicinais é uma importante fonte de recursos para cuidar da saúde. Nesse contexto, esse estudo objetivou fazer o levantamento da flora medicinal presentes nos quintais e utilizadas pela comunidade Mamangal, bem como, as indicações, as partes das plantas mais utilizadas, os modos de preparo dos remédios e verificar os valores de uso e a concordância de uso principal das espécies.

\section{MATERIAL E METODOS}

\section{1. Área de estudo}

A cidade de Igarapé-Miri está localizada na região nordeste do estado do Pará (Figura 1), também conhecida como região do Baixo Tocantins [22]. O município tem extensão territorial de $1.996,84 \mathrm{~km}^{2}$ e população estimada em 62.355 habitantes [23].

O município está inserido no estuário formado pelo Rio Tocantins, espaço constituído por muitas ilhas, igarapés e pequenos cursos d'agua, conhecidos na região como furos. Os rios mais importantes para cidade são o Meruú-Açu e Maiauatá, pois permitem o acesso a foz no Rio Tocantins e são navegáveis ao longo do ano, representando grandes propulsores para o desenvolvimento da região [24].

A comunidade Mamangal ( $01^{\circ} 53$ '274' 'S; 49 $\left.01^{\prime} 701^{\prime \prime} \mathrm{W}\right)$ situa-se as margens do Rio Mamangal Grande, entre os rios Meruú-Açu e Maiauatá, tendo como principal fonte de renda a extração do açaí, a pesca e o serviço público municipal ou estadual (Figura 1). Conforme os registros dos agentes comunitários de saúde havia 200 famílias residindo na comunidade no primeiro semestre de 2018.

A comunidade não tem posto de saúde, de forma que os moradores precisam se dirigir ao posto da vila Maiauatá ou para a sede do município quando necessitam de atendimento médico. Em razão disso os moradores fazem uso principalmente de plantas medicinais cultivadas nos próprios quintais para tratar dos problemas de saúde mais recorrentes entre os moradores, problemas intestinais e as verminoses, principalmente as crianças. A falta de água potável pode ser um dos fatores que contribuem para essa realidade, pois a água consumida na comunidade é captada diretamente do rio Mamangal Grande.

Um agravante dessa realidade, é que a comunidade não possui serviço de coleta do lixo doméstico pela prefeitura e todos resíduos sólidos produzidos pelos moradores são jogados diretamente no rio Mamangal Grande, queimados ou enterrados. 


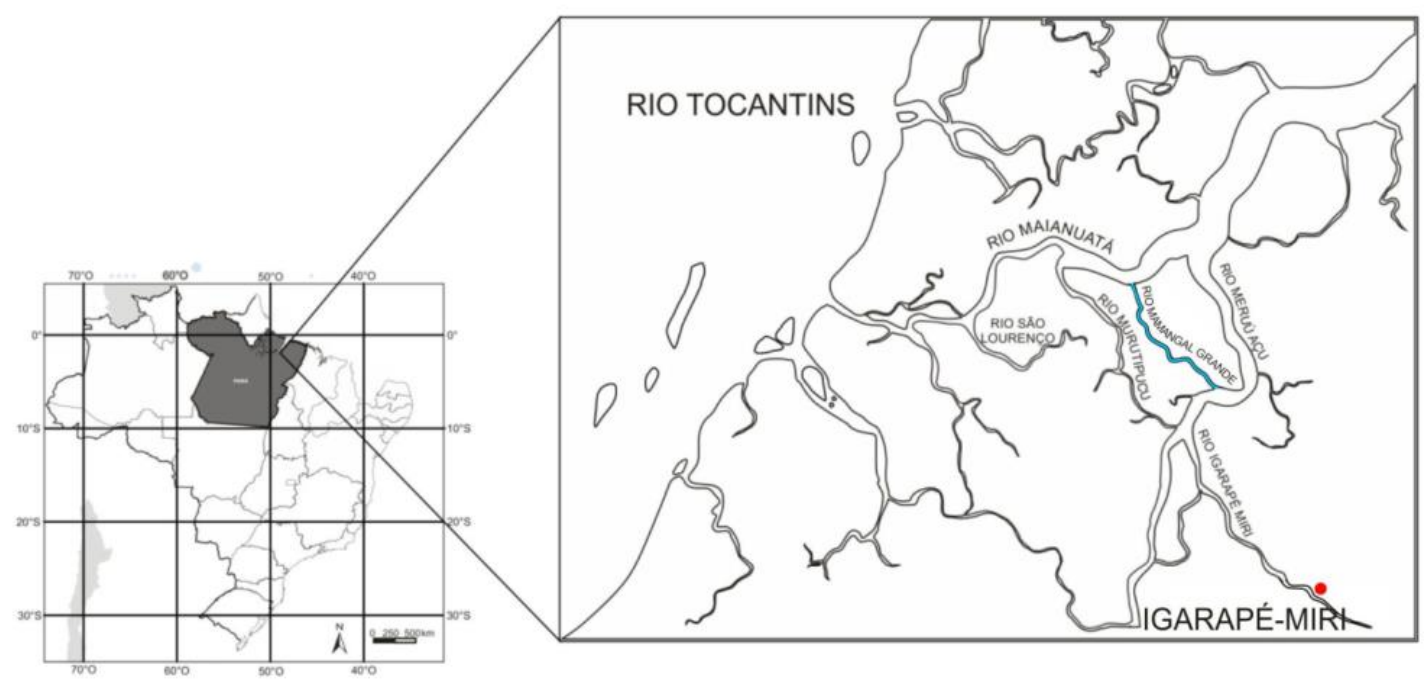

Figura 1. Mapa do Pará e localização do município de Igarapé-Miri, onde se encontra a localidade Mamangal, Pará.

\subsection{Amostragem e coleta dos dados}

A seleção dos colaboradores se deu através da metodologia "bola de neve" (snowball sampling) [25], o líder comunitário indicou o primeiro informante e este recomendou o próximo, repetindose o processo a partir de novos incluídos.

A pesquisa de campo foi realizada em três etapas: primeiramente visitamos o líder comunitário que indicou os possíveis participantes; na segunda fase aplicamos os questionários, explicamos os objetivos do projeto e os participantes fizeram a leitura do Termo de Consentimento Livre e Esclarecido (TCLE), esclarecemos dúvidas sobre o projeto e confirmamos o consentimento em participar da pesquisa; na terceira e última fase realizamos os procedimentos de coleta das amostras. A técnica da lista livre foi adotada, a qual consiste em citar componentes de um determinado domínio cultural na ordem que o participante lembrar, representando o conhecimento local e sua variação na comunidade [26].

A pesquisa fez parte do projeto "Etnoconhecimento de plantas medicinais cultivadas em quintais na comunidade Mamangal, Rio Meruú, Igarapé-Miri, Pará" e encontra-se cadastrado no Sistema Nacional de Gestão do Patrimônio Genético e do Conhecimento Tradicional Associado (SisGen), sob o número A2B82CE. A pesquisa foi submetida e aprovada no sistema da Plataforma Brasil e Comitê de Ética do Instituto de Ciências da Saúde (UFPA) com número de registro CAAE89148418.7.0000.0018.

\subsection{Identificação botânica}

As coletas dos espécimes vegetais e as visitas à comunidade Mamangal foi realizada por meio de turnê guiada. A herborização seguiu técnicas descritas por Ming (1996) [27] e sempre que possível, coletamos amostras férteis e registramos fotografias das plantas medicinais incluídas na amostra. A identificação das espécies teve como base literatura especializada e consultas aos sites: Flora do Brasil 2020 e Tropicos do Missouri Botanical Garden. As exsicatas encontram-se catalogadas e incorporadas à coleção biológica do Herbário do Instituto Federal do Pará, Campus Abaetetuba.

\subsection{Análise dos dados}

A importância das espécies para a comunidade Mamangal foi estimada usando o cálculo do valor de uso (VU), conforme Rossato et al. (1999) [28] e Phillips e Gentry (1993) [29]. A determinação da importância relativa foi calculada através da porcentagem de Concordância de Uso Principal (CUP) [30]. 


\section{RESULTADOS E DISCUSSÃO}

Esse estudo foi conduzido entre os meses de agosto e outubro de 2018, contou com 20 participantes, 19 mulheres e um homem, entre 30 e 76 anos de idade. O predomínio das mulheres corrobora com vários estudos etnobotânicos que atribuem o conhecimento sobre as plantas medicinais, predominantemente entre o gênero feminino [1, 2, 32, 33]. Em relação à faixa etária, segundo Viu et al. (2010) [31] esse é um fator importante sobre os conhecimentos acumulados do uso medicinal das plantas, pois nesse contexto a idade avançada pode indicar muita experiência em relação aos benefícios dos remédios caseiros.

Em relação ao grau de instrução, apenas um participante fez o curso de técnicas agrícolas, $85 \%$ tinha o ensino fundamental incompleto e $10 \%$ de analfabetos. Um levantamento etnobotânico realizado no município de Oliveira Fortes (MG) encontrou taxa de analfabetismo de $22 \%$ [32] e em uma comunidade rural piauiense $32,4 \%$ não escolarizados [26]. Um dos fatores que desestimula a dedicação à carreira estudantil na comunidade Mamangal são as atividades laborais relacionadas à monocultura do açaí. A cidade de Igarapé-Miri é uma das grandes produtoras de açaí do País e consequentemente, a coleta e o beneficiamento da polpa de açaí são considerados como as atividades mais lucrativas.

Quanto à origem dos colaboradores, observou-se que viviam na comunidade Mamangal desde que nasceram. Resultado diferente dos que foram descritos em uma comunidade rural piauiense, em que apenas $18,31 \%$ viviam na comunidade desde que nasceram [33] e na comunidade Ramal do Bacuri, localizada na zona rural de Abaetetuba, Pará, em que aproximadamente 50\% havia nascido na comunidade [11]. Foram relatadas 31 indicações e cinco formas de preparo dos remédios caseiro, o que evidencia amplo conhecimento local a respeito dos usos e da manipulação das plantas. Esses conhecimentos sobre o uso terapêutico das ervas foram passados das gerações anteriores e que novos saberes foram adquiridos, principalmente, das espécies a serem utilizadas como medicinais.

A comunidade Mamangal localiza-se as margens do rio Mamangal Grande e tem influência das marés. Logo, durante a maré cheia, os quintais ficam total ou parcialmente inundados. Em função disso, as plantas medicinais são cultivadas em canteiros suspensos, em vasilhas com alça de arame ou de cipó, dentro da própria residência e, no solo úmido, aquelas que toleram tal condição.

$\mathrm{O}$ deslocamento entre as residências dos mamangalenses pode ser feito pelo rio, usando pequenas embarcações denominadas de "rabudo", e por cimas de pontes de madeira. Essas estruturas foram encontradas em 42,5\% dos domicílios visitados, no espaço denominado de quintal, visando a locomoção ao redor da casa. Nesse ambiente peridomiciliar foi encontrado uma ampla diversidade de espécies, o que está em consonância com o conceito de quintal proposto por Sales et al. (2008) [34].

Foram identificadas 47 etnoespécies, das quais 37 foram identificadas em nível de espécies, distribuídas entre 36 gêneros e 24 famílias. As famílias que apresentaram o maior número de espécies foram, Lamiaceae (8 espécies) e Bignoniaceae (3 espécies) (Figura 2). Essas famílias também foram citadas como sendo as mais representativas em outros estudos etnobotânicos de plantas medicinais $[35,36]$. 


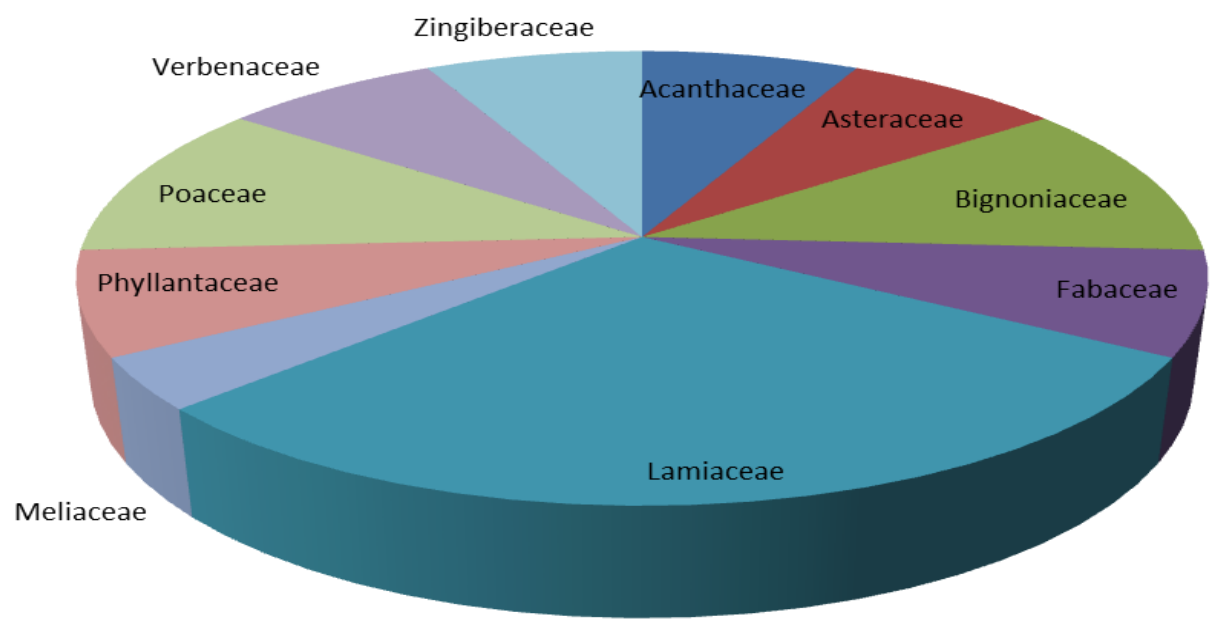

Figura 2. Famílias mais representativas no levantamento etnobotânico na comunidade Mamangal, Pará.

Na Tabela 1 estão descritas as diversas formas de manipulação medicinal e de usos das plantas na comunidade Mamangal. A indicação desses remédios caseiros, em geral, segue um ritual: relatar os casos em que o remédio funcionou; detalhar o modo de preparo; destacar as etapas mais importantes do tratamento que devem ser seguidas e as implicações em não as cumprir. Essa ritualística está de acordo com Zeni et al. (2017) [36] ao sugerir que o termo remédio caseiro abrange todos os aspectos de utilização das ervas para fins terapêuticos preparados em ambiente caseiro.

Na comunidade Mamangal a parte vegetal mais utilizada na elaboração de remédios foi a folha, na forma de chá. Segundo Vásquez et al. (2014) [6] o chá das folhas deve ser preparado por infusão, devido ser uma parte tenra da planta e a decocção, recomendada para as partes mais consistentes como as cascas. Nessa pesquisa foi observada a preparação de chás simples e mistos, corroborando com os resultados relatados em $47,6 \%$ das preparações de chás terapêuticos na comunidade Rio Urubueua de Fátima na cidade de Abaetetuba, Pará [37].

As plantas medicinais que compõe a fitofarmacopeia da comunidade em estudo estão distribuídas em quatro hábitos: Erva (70\%), Árvore (18\%), Arbusto (9\%) e Liana (3\%). Segundo Neto e Amaral (2010) [38] a preferência por ervas pode ser devido ao pouco espaço que ocupam e ainda podem facilmente serem plantadas aos arredores das residências. Dessa forma, ambientes como os quintais são os mais explorados, pois é onde se encontram a maioria das plantas medicinais citadas $(73,91 \%)$. Os quintais são muito explorados, por serem extensos ambientes em volta das casas, onde basicamente são ocupados por plantas úteis (medicinais e frutíferas). Plantas utilizadas contra problemas de saúde frequentes devem ficar mais acessíveis e, portanto, devem ser cultivadas próximas às habitações [30].

Na comunidade Mamangal as espécies de plantas medicinais cultivadas em quintis são aplicadas nos cuidados a saúde para o tratamento de problemas gastrointestinais (32\% das indicações), sintomas em geral (29\% das indicações), doenças respiratórias (16\% das indicações) e processos inflamatórios e infecções (23\% das indicações). Segundo um estudo desenvolvido por Gois et al. (2016) [39] as diversas formas como as plantas medicinais são usadas na medicina popular, reflete o espectro de problemas de saúde enfrentados pelas comunidades ribeirinhas na Amazônia, como consequência dos problemas sanitários e a precariedade da assistência médica convencional. 
Tabela 1. Aspectos etnobotânicos da flora medicinal de quintais usada pelos moradores na comunidade Mamangal, Pará.

\begin{tabular}{|c|c|c|c|c|}
\hline Etnoespécies & Família & Nome científico & Indicação & Preparo e usos \\
\hline Alho folha & Bignoniaceae & $\begin{array}{l}\text { Mansoa standleyi (Steyerm.) } \\
\text { A.H.Gentry }\end{array}$ & Pressão alta & Chá (folhas) \\
\hline $\begin{array}{l}\text { Amor } \\
\text { crescido }\end{array}$ & Portulacaceae & $\begin{array}{l}\text { Portulaca subsect. Pilosae D. } \\
\text { Legrand }\end{array}$ & $\begin{array}{l}\text { Lavar os } \\
\text { cabelos }\end{array}$ & $\begin{array}{l}\text { Chá (planta inteira): amassar a } \\
\text { planta e acrescentar um pouco } \\
\text { de água e colocar para ferver }\end{array}$ \\
\hline Anador & Lamiaceae & Plectranthus neochilus Schltr & Dor de barriga & $\begin{array}{l}\text { Chá (folhas): misturar com } \\
\text { boldo, marupá e hortelã }\end{array}$ \\
\hline Andiroba & Meliaceae & Carapa guianensis Aubl. & $\begin{array}{l}\text { Infecção e dores } \\
\text { na garganta }\end{array}$ & $\begin{array}{l}\text { Óleo: tomar algumas gotas do } \\
\text { óleo }\end{array}$ \\
\hline Anecrosan & N.I & & Dor no fígado & $\begin{array}{l}\text { Chá (folhas): misturar com as } \\
\text { folhas de anecrosan, chama, } \\
\text { pirarucu, casca de laranja e } \\
\text { ferver }\end{array}$ \\
\hline $\begin{array}{l}\text { Araçá do } \\
\text { sertão }\end{array}$ & Myrtaceae & Psidium arboreum Vell. & $\begin{array}{l}\text { Inflamação em } \\
\text { geral }\end{array}$ & Chá (folhas) \\
\hline Arruda & Rutaceae & Ruta graveolens L. & $\begin{array}{l}\text { Febre } \\
\text { Derrame }\end{array}$ & $\begin{array}{l}\text { Planta inteira: amassar tudo e } \\
\text { misturar com um copo de água } \\
\text { e ferver }\end{array}$ \\
\hline Babosa & N.I & & $\begin{array}{l}\text { Queimadura de } \\
\text { pele }\end{array}$ & $\begin{array}{l}\text { Tirar o gel de dentro da folha } \\
\text { da babosa e colocar em cima da } \\
\text { queimadura }\end{array}$ \\
\hline Boldo & Lamiaceae & Plectranthus ornatos Codd & $\begin{array}{l}\text { Infecção } \\
\text { intestinal }\end{array}$ & Chá (folhas) \\
\hline Boldo planta & Asteraceae & Vernonia condensata Baker & $\begin{array}{l}\text { Estômago cheio } \\
\text { de gases e lento }\end{array}$ & Chá (folhas) \\
\hline Canafistola & Costaceae & Eleutherine bulbosa (Mil.) Urb. & $\begin{array}{l}\text { Infecção } \\
\text { urinária }\end{array}$ & $\begin{array}{l}\text { Chá (folhas): misturar com } \\
\text { sucuriju e amor crescido }\end{array}$ \\
\hline Canela & Lauraceae & Cinnamomum verum J. Presl. & Estresse & Chá (folhas) \\
\hline $\begin{array}{l}\text { Capim } \\
\text { marinho }\end{array}$ & Poaceae & Cymbopogon citratus (DC.) Stapf & Pressão alta & Chá (planta inteira) \\
\hline Capim santo & Poaceae & Citratus citratus (L.) Stapf & Pressão alta & Chá (folhas) \\
\hline $\begin{array}{l}\text { Catinga de } \\
\text { mulata }\end{array}$ & Lamiaceae & $\begin{array}{l}\text { Aelloanthus suaveolens Mart. ex } \\
\text { Spreng }\end{array}$ & $\begin{array}{l}\text { Aperreação de } \\
\text { criança. } \\
\text { Gripe }\end{array}$ & $\begin{array}{l}\text { Chá (folhas): Amassar a planta } \\
\text { e misturar: pucá, arruda, } \\
\text { gengibre preto, água ardente } \\
\text { alemã, óleo elétrico, vinagre } \\
\text { aromático e mucuracaá }\end{array}$ \\
\hline Caxinguba & Moraceae & Ficus insipida Willd. & Vermes & $\begin{array}{l}\text { Xarope: cortar a casca e colocar } \\
\text { para ferver, depois coar, tirar o } \\
\text { suco e misturar com leite } \\
\text { condensado e voltar a ferver } \\
\text { uns } 30 \text { minutos }\end{array}$ \\
\hline Chicória & Apiaceae & Eryngium foetidum L. & $\begin{array}{l}\text { Dentição de } \\
\text { crianças }\end{array}$ & $\begin{array}{l}\text { Chá (raízes): misturar com } \\
\text { chama e hortelã }\end{array}$ \\
\hline $\begin{array}{l}\text { Comida de } \\
\text { jabuti }\end{array}$ & Piperaceae & Peperomia pellucida (L.) Kunth & Diabetes & Chá (folhas) \\
\hline Erva cidreira & Verbenaceae & $\begin{array}{l}\text { Lippia alba (Mill.) N.E.Br. ex P. } \\
\text { Wilson }\end{array}$ & Baixar pressão. & Chá (folhas) \\
\hline Erva santa & N.I & & $\begin{array}{l}\text { Gripe, Tosse, } \\
\text { Catarro no peito }\end{array}$ & $\begin{array}{l}\text { Geleia: colocar as folhas com } \\
\text { açúcar e um pouco de água em } \\
\text { fogo brando. Mexer lentamente } \\
\text { até a calda ficar grossa e de cor } \\
\text { escura. Usar uma colher todo } \\
\text { dia pela manhã e depois tomar } \\
\text { banho }\end{array}$ \\
\hline Favaca & Lamiaceae & Ocimum gratissimum L. & Diabetes & Chá (folhas) \\
\hline
\end{tabular}




\begin{tabular}{|c|c|c|c|c|}
\hline Forsangue & Acanthaceae & Justicia secunda Vahl & Anemia & $\begin{array}{l}\text { Chá (folhas): ferver bem a } \\
\text { folha até o caldo ficar bem } \\
\text { vermelho }\end{array}$ \\
\hline Gengibre & Zingiberaceae & Zingiber officinale Roscoe & Reumatismo & $\begin{array}{l}\text { Chá (raízes): ferver e depois } \\
\text { fazer compressas nas regiões } \\
\text { afetadas }\end{array}$ \\
\hline $\begin{array}{l}\text { Hortelã } \\
\text { branco }\end{array}$ & Lamiaceae & Mentha sp. & $\begin{array}{l}\text { Estômago } \\
\text { pesado }\end{array}$ & $\begin{array}{l}\text { Chá (folhas): misturar: marcela, } \\
\text { gengibre, hortelãzinha e } \\
\text { mastruz }\end{array}$ \\
\hline $\begin{array}{l}\text { Hortelã do } \\
\text { maranhão }\end{array}$ & Lamiaceae & Marrubium hamatum Kunth & $\begin{array}{l}\text { Tosse com } \\
\text { catarro no peito }\end{array}$ & $\begin{array}{l}\text { Chá (folhas): misturar a folha } \\
\text { com jamaracarú, algodão e } \\
\text { laranja da terra e colocar para } \\
\text { ferver }\end{array}$ \\
\hline $\begin{array}{l}\text { Hortelã } \\
\text { Verde }\end{array}$ & N.I & & $\begin{array}{l}\text { Dor no } \\
\text { estômago }\end{array}$ & $\begin{array}{l}\text { Chá (folhas): ferver a folha } \\
\text { com dois copos de água }\end{array}$ \\
\hline $\begin{array}{l}\text { Hortelãnzinh } \\
\text { o }\end{array}$ & N.I & & $\begin{array}{l}\text { Dor de } \\
\text { estômago }\end{array}$ & $\begin{array}{l}\text { Chá (folhas): misturar com a } \\
\text { marcela, gengibre, hortelã } \\
\text { branco e mastruz }\end{array}$ \\
\hline Jucá & Fabaceae & $\begin{array}{l}\text { Libidibia ferrea (Mart. ex Tul.) } \\
\text { L.P.Queiroz }\end{array}$ & $\begin{array}{l}\text { Todos os tipos } \\
\text { de infecção } \\
\text { Inflamação }\end{array}$ & $\begin{array}{l}\text { Chá (folhas): ferver com água, } \\
\text { coar e tomar }\end{array}$ \\
\hline Manjerição & Lamiaceae & Ocimum basilicum $\mathrm{L}$. & $\begin{array}{l}\text { Tosse com } \\
\text { catarro. }\end{array}$ & $\begin{array}{l}\text { Chá (folhas): ferver junto com } \\
\text { a gemada de ovo }\end{array}$ \\
\hline Manjerona & Verbenaceae & Lippia thymoides Mart. \& Schauer & $\begin{array}{l}\text { Banho de cheiro } \\
\text { e mal olhado }\end{array}$ & $\begin{array}{l}\text { Banho: juntar com pataqueira, } \\
\text { mangericão e beliscão }\end{array}$ \\
\hline Marcela & N.I & & $\begin{array}{l}\text { Azia. } \\
\text { Má digestão }\end{array}$ & $\begin{array}{l}\text { Chá (folhas): Ferve a folha } \\
\text { com: hortelãnzinho, boldo, } \\
\text { boldo de planta e erva doce }\end{array}$ \\
\hline Marupazinho & Iridaceae & Eleutherine bulbosa (Mil.) Urb. & $\begin{array}{l}\text { Criança com } \\
\text { dentição } \\
\text { Diarreia com } \\
\text { sangue }\end{array}$ & $\begin{array}{l}\text { Chá (raízes): cortar a raiz e } \\
\text { misturar com hortelã branco, } \\
\text { chama, e terramicina }\end{array}$ \\
\hline Mastruz & Amaranthaceae & Chenopodium ambrosioides L. & $\begin{array}{l}\text { Peito aberto } \\
\text { Dor de } \\
\text { estômago }\end{array}$ & $\begin{array}{l}\text { Xarope: Misturar com marcela, } \\
\text { gengibre e mel de abelha }\end{array}$ \\
\hline Mucuracaá & Phytolaceaceae & Petiveria alliaceae $\mathrm{L}$. & Dor de barriga & $\begin{array}{l}\text { Chá (folhas): mistura com } \\
\text { mucuracaá, anador e um copo } \\
\text { de água, coar e beber }\end{array}$ \\
\hline Noni & Rubiaceae & Morinda citrifolia $\mathrm{L}$. & $\begin{array}{l}\text { Anti- } \\
\text { inflamatório }\end{array}$ & $\begin{array}{l}\text { Chá (frutos): cortar o fruto em } \\
\text { cubos e ferver }\end{array}$ \\
\hline Pariri & Bignoniaceae & $\begin{array}{l}\text { Fridericia chica (Bonpl.) L.G. } \\
\text { Lohmann }\end{array}$ & Anemia & Chá (folhas) \\
\hline Pata de vaca & Fabaceae & Bauhinia forficata Link & $\begin{array}{l}\text { Infecção } \\
\text { Diabetes }\end{array}$ & $\begin{array}{l}\text { Chá (folhas): } 2 \text { folhas de pata } \\
\text { da vaca e um copo de água }\end{array}$ \\
\hline Pataqueira & Scrophulariaceae & $\begin{array}{l}\text { Conobea scoparioides Cham. \& } \\
\text { Schltdl }\end{array}$ & Banho de cheiro & $\begin{array}{l}\text { Banho: misturar com } \\
\text { manjericão e ferver }\end{array}$ \\
\hline Pião roxo & Euphorbiaceae & Jatropha gossypiifolia $L$. & $\begin{array}{l}\text { Pneumonia. } \\
\text { Bronquite }\end{array}$ & $\begin{array}{l}\text { Chá (folhas, flores e frutos): } \\
\text { ferver com água durante } 30 \\
\text { minutos }\end{array}$ \\
\hline Pirarucu & Crassulaceae & Kalanchoe pinnata (Lam.) Pers. & $\begin{array}{l}\text { Infecções. } \\
\text { Gastrite }\end{array}$ & $\begin{array}{l}\text { Chá (folhas): bater a folha junto } \\
\text { com leite condensado }\end{array}$ \\
\hline Pucá & Melastomaraceae & $\begin{array}{l}\text { Cissus verticilata (L.) Nicolson \& } \\
\text { C.E. Javis }\end{array}$ & $\begin{array}{l}\text { Febre } \\
\text { Derrame }\end{array}$ & $\begin{array}{l}\text { Banho: ferver a folha com um } \\
\text { copo de água e depois misturar } \\
\text { com álcool. Passar várias vezes } \\
\text { durante o dia na parte do corpo } \\
\text { afetada ou dar o banho }\end{array}$ \\
\hline $\begin{array}{l}\text { Quebra } \\
\text { pedra }\end{array}$ & Phyllantaceae & Phyllanthus niruri L. & Dor nos rins & $\begin{array}{l}\text { Chá (folhas): juntar quebra- } \\
\text { pedra, sucuriju, babosa e água } \\
\text { para ferver, depois coar e beber }\end{array}$ \\
\hline
\end{tabular}




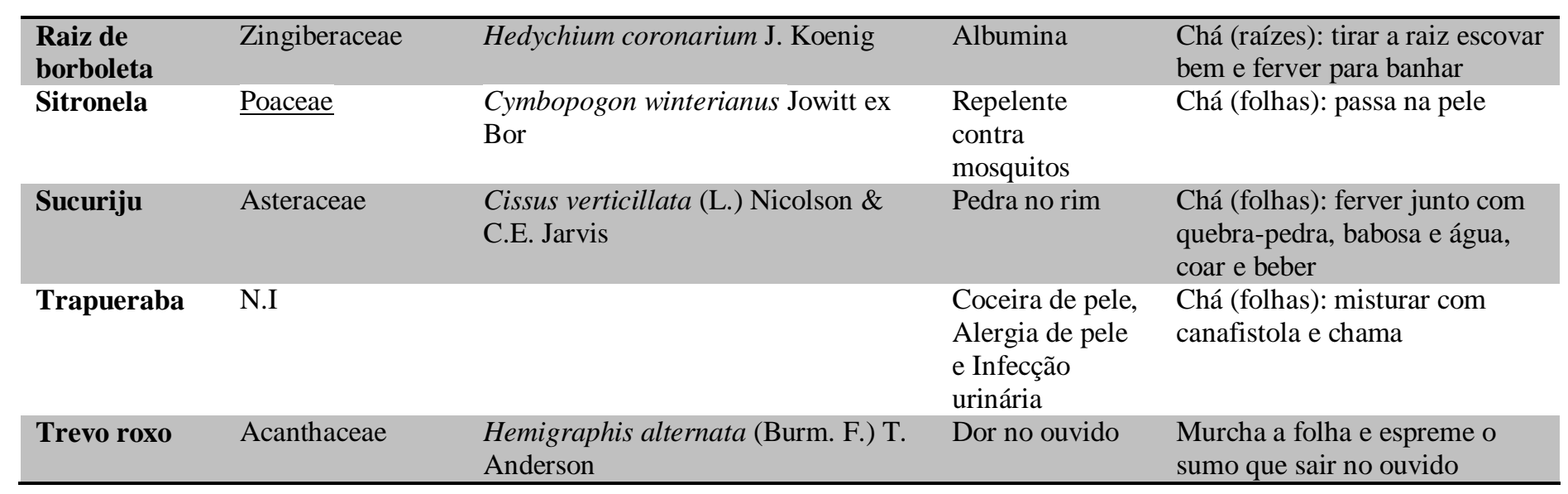

Acerca do consenso de uso entre os colaboradores, nove espécies medicinais apresentaram valores de consenso de uso principal superior a 25\%. As plantas arruda (Ruta graveolens L.), mastruz (Chenopodium ambrosioides L.) e pariri (Fridericia chica (Bonpl.) L.G. Lohmann) apresentaram valor de CUPs maior que 50\%, indicando um apreciável consenso de uso popular e potencial medicinal. A arruda foi a etnoespécie que apresentou a CUPs mais alta, com 87,5\% usada para o tratamento de derrame, seguida de pariri $(62,11 \%)$ indicada para combater anemia e matruz $(55,80 \%)$ receitado contra problemas gastrointestinais.

O maior valor de CUPs para cada espécie equivale ao maior número pessoas que relataram a mesma forma de uso para a mesma planta, sugerindo maior concordância de uso na comunidade em estudo. Elevados valores de uso de uma determinada espécie de vegetal, reforça a concordância de uso, o que pode servir de parâmetro para estudos farmacológicos no futuro. Segundo Roque et al. (2010) [40] estudos etnobotânicos da flora medicinal de quintais podem ser uteis como uma triagem de plantas que poderão ser usadas para bioprospecção de biomoléculas com potencial terapêutico para descoberta de novos fitoterápicos ou melhorar os já existentes e estabelecer novas perspectivas de tratamentos alternativos.

$\mathrm{O}$ valor de VU das espécies foi calculado, encontrando valores que variaram entre 0,02 a 0,25 , sendo os valores mais expressivos: hortelã do maranhão, pião roxo, comida de jabuti, boldo planta, mastruz e canela. Entretanto, amor crescido com 17 citações apresentou VU $(0,01)$ e catinga de mulata $(0,02)$ com todas as citações. Segundo Neto et al. (2018) [32], pode-se inferir que a importância das espécies não está relacionada diretamente ao número de indivíduos que as usam, mas sim ao número de indicações terapêuticas.

A espécie Chenopodium ambrosioides L. (mastruz) foi à única que apresentou valores de VU e CUPs significativos, corroborando com os resultados descritos por Costa e Marinho (2016) [41] em um estudo realizado no município de Picuí (PB). Estudos etnobotânicos em localidades diferentes indicaram o mastruz para diversas afecções, como o chá das folhas para o tratamento de problemas intestinais, cicatrização de ferimentos na pele e anti-inflamatório [42]; o sumo da planta inteira para inflamação do sistema respiratório [43] e o suco das folhas para combater parasitas intestinais [44].

Ao analisar vários estudos sobre o conhecimento popular do mastruz percebemos discrepâncias quanto às formulações, indicações e o modo de uso, contudo notamos o predomínio do uso desse vegetal para tratar afecções intestinais [44, 42, 43]. De acordo com Theisen et al. (2015) [45], os conhecimentos sobre as diversas formas de cura representam saberes locais, transmitidos genuinamente através da oralidade e de gestos, comunicada por intermédio da família e da vizinhança.

\section{CONCLUSÃO}

Os quintais da comunidade Mamangal apresentaram elevada diversidade de espécies utilizadas na medicina local. Essa flora medicinal tem grande importância para a população, pois as diversas formas de preparo e de usos desses remédios caseiros visam atender as demandas dos mamangalenses principalmente em relação a infecções intestinais. 


\section{AGRADECIMENTOS}

À Universidade Federal do Pará e ao Herbário do Instituto Federal do Pará-Campus Abaetetuba. Aos Colaboradores que aceitaram participar dessa pesquisa.

\section{REFERÊNCIAS BIBLIOGRÁFICAS}

1. Silva PH, Oliveira YR, Abreu MC. Uma abordagem etnobotânica acerca das plantas úteis cultivadas em quintais em uma comunidade rural do semiárido piauiense, Nordeste do Brasil. J Environm Anal Progr. 2017;2(2):144-159. doi: 10.24221/jeap.2.2.2017.1179.115-124.

2. Penido AB, Moraes SM, Ribeiro AB, Silva AZ. Ethnobotanical study of medicinal plants in Imperatriz, State of Maranhão, Northeastern Brazil. Acta Amaz. 2016;64(4):345-354. doi: 10.1590/18094392201600584.

3. Leite IA, Morais AM, Silva de Ó KD, Carneiro RG, Leite CA. A etnobotânica de plantas medicinais no município de São José de Espinharas, Paraíba, Brasil. Biodiversidade. 2015;14(1):22-30.

4. Giraldi M, Hanazaki N. Uso e conhecimento tradicional de plantas medicinais no Sertão do Ribeirão, Florianópolis, SC, Brasil. Act Bot Bras. 2010;24(2):395-406.

5. Gonçalves NMT, Gerenutti M, Chaves DAS, Vila MMDC. A tradição popular como ferramenta para implantação da fitoterapia no município de Volta Redonda, RJ. Rev Bras Farm. 2011;92(4):346-351.

6. Vásquez SPF, Mendonça MS, Noda SN. Etnobotânica de plantas medicinais em comunidades ribeirinhas do município de Manacapuru, Amazonas, Brasil. Acta Amaz. 2014;44(4):457-472. doi: 10.1590/18094392201400423.

7. Flor ASSO, Barbosa WLR. Sabedoria popular no uso de plantas medicinais pelos moradores do bairro do sossego do distrito de Marudá-PA. Rev Bras Pl Med. 2015;17(4):757-768. doi: 10.1590/1983084X/14_064

8. Leandro YAS, Jardim IN, Gavilanes ML. Uso de plantas medicinais nos cuidados de saúde dos moradores de assentamento no município de Anapu, Pará, Brasil. Biodiversidade. 2017;16(20):30-44.

9. Santos JJF, Coelho-Ferreira M, Lima PGC. Etnobotânica de plantas medicinais em mercados públicos da Região Metropolitana de Belém do Pará, Brasil. Biota Amaz. 2018;8(1):1-9. doi: 10.18561/21795746/biotaamazonia.v8n1p1-9

10. Palheta IC, Tavares-Martis ACC, Lucas FCA, Jardim MAG. Ethobotanical study of medicinal plants in urban home gardens in the city of Abaetetuba, Pará State, Brasil. Bol Latinoam Del Caribe Plantas Med Aromát. 2017;16(3):206-262.

11. Lobato GJM, Lucas FCA, Junior MRM. Estética, crenças e ambiência: as representatividades plantas ornamentais em quitais urbanos de Abaetetuba-Pará. Ambiência Guarapueva. 2017 jan/abril; 13(1):135149. doi: 10.5935/ambiência.2017.01.09.

12. Trotta J, Messias PA, Pires AHC, Hayashida CT, Camargo C, Futema C. Análise do conhecimento e uso popular de plantas de quintais urbanos no Estado de São Paulo, Brasil. Rev Estudos Amb. 2012 jan/jun; 14(3):17-34. doi: 10.7867/1983-1501.2012v14n3p17-34

13. Gonçalves JP, Lucas FCA. Agrobiodiversidade e etnoconhecimento em quintais de Abaetetuba, Pará, Brasil. Rev Bras Biociênc. 2017;15(3):119-134.

14. Pinto ALA, Sousa FJF, Rufino MSM. Conhecimento etnobotânico dos Tremembé da Barra do Mundaú sobre as frutas da sociobiodiversidade. Interações. 2019 jan/mar;20(1):327-339. doi: 10.20435/inter.v19i4.1632.

15. Oliveira LS. Estudo etnobotânico da comunidade rural Cinturão Verde Boa Vista-Pedra 90 Cuibá-MT Brasil. Biodiversidade. 2019;18(1):114-128.

16. Cruz VMS, Gonçalves AL, Campos JRP, Reis ARS. Aspectos socioeconômicos e o cultivo de plantas medicinais em quintais agroflorestais urbanos (QAF) no município de Breu Branco, Pará, Brasil. Enciclopédia Biosfera. 2017;14(25):158-170. doi: 10.18677/encibio-2017a15.

17. Rodrigues KA, Oliveira LS, Neto FR, Araújo MP, Gomes DCV. O uso de plantas medicinais pela comunidade da zona norte de Teresina-PI e seu fins terapêuticos. Rev Interdiscip. 2017;10(4):77-81.

18. Neri GF, Oliveira TL, Oliveira VJS, Brito NM. Uso de plantas medicinais nas unidades de saúde da família do Alto Sobradinho e Cocão do município de Santo Antônio de Jesus-BA. Ensaios Cienc. 2018;22(1):58-62. doi: 10.17921/1415-6938.2018.

19. de Sousa RL, Almeida BB, Silva RP, Albuquerque LCS, Cordeiro YEM. Óleo de andiroba: extração, comercialização e usos tradicionais na comunidade Mamangal, Igarapé-Miri, Pará. Biodiversidade. 2019;18(1):68-81. 
20. Costa JC, Marinho MGV. Etnobotânica de plantas medicinais em duas comunidades do município de Picuí, Paraíba, Brasil. Rev Bras Pl Med. 2016;18(1):125-134. doi: 10.1590/1983-084X/15-071.

21. Ferreira LR, Tavares-Martins ACC. Química e etnofarmacologia de plantas místicas em uma comunidade amazônica. Rev Fitos. 2017 jul-set;10(3):220-372. doi: 10.5935/2446-4775.20160024

22. Pinto LN, Flor ASSO, Barbosa WLR. Fitoterapia popular na Amazônia Paraense: uma abordagem no município de Igarapé-Miri, estado do Pará nos anos de 2000 e 2008. Rev Ciênc Farm Básica Apl. 2014;35(2):305-311.

23. IBGE. Instituto Brasileiro de Geografia e Estatística. Conheça cidades e estados do Brasil. Disponível em: http://cidades.ibge.gov.br. Acesso em 26/01/2019.

24. Cunha EM. Mutirão e trabalhadores de Igarapé-Miri: açaí como alternativa econômica no contexto de gênero. Papers do NAEA no 206. 2006 dez.

25. Albuquerque UP, Lucena RFP, Lins Neto EMF. Seleção dos participantes da pesquisa. In. Albuquerque UP, Lucena RFP, Cunha LVFC. (Org.). Métodos e técnicas na pesquisa etnobiológica e etnoecológica. Recife, PE: NUPEEA, 2010.

26. Quinlan M. Considerations for collecting freelists in the field: examples from Ethobotany. Field Methods. 2005;17(3):1-16.

27. Ming LC. Coleta de plantas medicinais. In: DI Stasi L C. (Org.). Plantas Medicinais: Arte e Ciência - Um Guia de Estudo Interdisciplinar. São Paulo: Editora da Universidade Estadual Paulista, 1996.

28. Rossato SC, Leitão-Filho HF, Begossi A. Ethnobotany of Caiçaras of the Atlantic Forest Coast (Brazil). Econ Bot. 1993;53(4):387-395.

29. Phillips O, Gentry AH. The useful plants of Tambopata, Peru: I. statistical hypotheses test with a new quantitative thechnique. Econ Bot. 1993;47(1):15-32.

30. Amaorozo MCM, Gély A. Uso de plantas medicinais por caboclos do Baixo Amazonas, Barcarena, PA, Brasil. Bol Mus Para Emílio Goeldi. 1988;4(1):47-131.

31. Viu AFM, Viu MAO, Campos LZ. Etnobotânica: uma questão de gênero? Rev Bras Agroecol. 2010;5(1):138-147.

32. Neto LAG, Gomes FT. Levantamento etnobotânico de plantas medicinais utilizadas pela população do município de Oliveira Fortes - MG. Rev Semina. 2018;8(27):1-17. doi: 10.25242/886882720181319.

33. Silva PH, Oliveira YR, Abreu MC. Entre símbolo, mistérios e a cura: plantas místicas dos quintais de uma comunidade rural piauiense. Gaia Scientia. 2018;12(1):1-16. doi: 10.22478/ufpb.1981$1268.2018 \mathrm{v} 12 \mathrm{n} 1.33196$

34. Sales JP, Noda SN, Mendonça MAF, Branco FMC. A pecuária nos sistema de produção familiar na microrregião do Alto Solimões, Amazônia. Rev Bras Agroecol. 2008;3(1):20-27.

35. Neri G, Oliveira TL, Oliveira VJS, Brito NM. Uso de plantas medicinais nas unidades de Saúde da família do Alto Sobradinho e Cocão do município de Santo Antônio de Jesus-BA. Ensaios Cienc. 2018;22(1):5862. doi: 10.17921/1415-6938.

36. Zeni ALB, Parisotto AV, Mattos G, Helena ETS. Utilização de plantas medicinais como remédio caseiro na atenção primária em Blumenau, Santa Catarina, Brasil. Ciência \& Saúde Coletiva. 2017;22(8):27032712. doi:10.1590/1413-81232017228.18892015.

37. Moura PHB, Lucas FCA, Tavares-Martins ACC, Lobato GJM, Gurgel ESC. Etnobotânica de chás terapêuticos em Rio Urubueua de Fátima, Abaetetuba-Pará, Brasil. Biotemas. 2016;29(2):77-88. doi: 10.5007/2175-7925.2016.

38. Neto GG, Amaral CN. Aspectos etnobotânicos de quintais tradicionais dos moradores de Rosário Oeste, Mato Grosso, Brasil. Polibotánica. 2010;29:191-212.

39. Gois MAF, Lucas FCA, Costa JCM, Moura PHB, Lobato GJM. Etnobotânica de espécies vegetais no tratamento de transtornos do sistema gastrointestinal. Rev Bras Pl Med. 2016; 18(2):547-557. doi: 10.1590/1983-084X/15_170

40. Roque AA, Rocha RM, Loiola MIB. Uso e diversidade de plantas medicinais da Caatinga na comunidade rural de Laginhas, município de Caicó, Rio Grande do Norte (nordeste do Brasil). Rev Bras Pl Med. 2010;12(10):31-42.

41. Costa JC, Marinho MGV. Etnobotânica de plantas medicinais em duas comunidades do município de Picuí, Paraíba, Brasil. Rev Bras Pl Med. 2016;(1):125-134. doi: 10.1590/1983-084X/15_071.

42. Borges RM, Moreira RPM. Estudo etnobotânico de plantas medicinais no município de Confresa Mato Grosso, Brasil. Biodiversidade. 2016;15(3):68-82.

43. Novais AM, Neto GG, Guarim VLMS, Pasa MC. Os quintais e a flora local: um estudo na comunidade Jardim Paraiso, Carceres-MT, Brasil. Biodiversidade. 2011;10(1):3-12.

44. Oliveira VB, Rocha MCA. Levantamento de plantas utilizadas como medicinais na cidade de CaxiasMA: uma perspectiva etnofarmacológica. Rev Interd. 2016 out. nov;9(4):43-52. 
45. Theisen GR, Borges GM, Vieira MF. Implantação de uma horta medicinal e condimentar para uso da comunidade escolar. Rev Eletrônica Gest Educ Tecnol Amb. 2015 jan-abr; 19(1):167-171. doi: $10.5902 / 2236117015546$. 